\title{
Characterization and Electrochemical Behavior of Graphene-Based Anode for Li-Ion Batteries
}

\author{
Wei-Ren Liu ${ }^{*}{ }^{1,2}$, Shin-Liang Kuo ${ }^{1}$, Chia-Yi Lin ${ }^{2}$, Yi-Chen Chiu ${ }^{1}$, Ching-Yi Su ${ }^{1}$, Hung-Chun Wu ${ }^{1}$ \\ and Chien-Te Hsieh ${ }^{*}, 3$
}

\author{
${ }^{I}$ Material and Chemical Research Laboratories, ITRI, Hsinchu 300, Taiwan, R.O. China \\ ${ }^{2}$ Department of Chemical Engineering, Chung Yuan Christian University, 200, Chung Pei Rd., Chung Li, 32023, \\ Taiwan, R.O. China \\ ${ }^{3}$ Department of Chemical Engineering and Materials Science, Yuan Ze Fuel Cell Center, Yuan Ze University, Taoyuan \\ 320, Taiwan, R.O. China
}

\begin{abstract}
In this study, we investigate the characteristics and electrochemical properties of graphene nanosheets derived from chemical-thermal exfoliation processes of SFG44 synthetic graphite (SFG44-GNS). The characterizations and electrochemical measurements were carried out by means of X-ray diffraction, scanning electron microscopy, transmission electron microscopy, cyclic voltammetry, BET, Raman, rate capability as well as cycling tests and AC impedance. The as-synthesized SFG44-GNS with larger d-spacing of $0.3407 \mathrm{~nm}$ exhibits reversible capacity of 626 $\mathrm{mAh} / \mathrm{g}$ and good rate capability of $\sim 300 \mathrm{mAh} / \mathrm{g}$ at $2 \mathrm{C}$ rate, which are superior to those of graphite anode. The enhanced electrochemical performance of GNS anode was resulted from larger d-spacing, lower impedance in the interface and enhanced pore volume. The results indicate that graphene-based material is a good candidate for HEV/EV application.
\end{abstract}

Keywords: Graphene, Anode, Li-ion battery, Exfoliation.

\section{INTRODUCTION}

Graphene, one atom thick two dimensional layers of $\mathrm{sp}^{2}$ bonded carbon, has been emerging as a fascinating material with many unusual physical, chemical and mechanical properties. Thus, much attention has been drawn in technology applications, such as solar cells, hydrogen storage, supercapacitors and batteries [1-5]. Among these energy storage systems, lithium-ion batteries (LIB) are currently the predominant power sources for portable electronic devices and electrical/hybrid vehicles. Graphite is widely used as an anode material for commercial rechargeable LIBs due to its excellent cycle life. However, lower theoretical capacity of $372 \mathrm{mAh} \mathrm{g}^{-1}$ and poor rate capability limit its application on electrical/hybrid vehicles. Recently, a new kind of carbon material, graphene (or graphene nanosheets, namely GNS) obtained from exfoliation of graphite by chemical method, might be a potential alterative anode materials for LIB applications. Such as Paek et al., [6] and Yao's group [7] reported $\mathrm{SnO}_{2}$ /graphene composites delivered a reversible capacity of $810 \mathrm{mAh} \mathrm{g}^{-1}$ and $765 \mathrm{mAh} \mathrm{g}{ }^{-1}$, respectively. Yoo et al., [8] studied the electrochemical performance of graphene/CNT and graphene $/ \mathrm{C}_{60}$ composites, of which the capacities were $730 \mathrm{mAh} \mathrm{g}^{-1}$ and $780 \mathrm{mAh} \mathrm{g}^{-1}$, respectively. Wang et al., discussed the application of GNS as an anode material, giving a reversible capacity of $650 \mathrm{mAh} \mathrm{g}^{-1}$ in the first cycle [9]. Chou et al., demonstrated nanosize

*Address correspondence to these authors at the Material and Chemical Research Laboratories, ITRI, Hsinchu 300, Taiwan, R.O. China; Fax: +8863-5723764; E-mail: WRLiu@itri.org.tw and Department of Chemical Engineering and Materials Science, Yuan Ze Fuel Cell Center, Yuan Ze University, Taoyuan 320, Taiwan, R.O. China;

E-mail: cthsieh@staurn.yzu.edu.tw silicon/graphene composite anode with 1:1 wt. ratio showed a high capacity of $2158 \mathrm{mAh} / \mathrm{g}$ in the first cycle and $1168 \mathrm{mAh} \mathrm{g}^{-1}$ after 30 cycles [10].

Here, we report the rate capability of graphene nanosheets synthesized by modified Hummer's method. Their corresponding crystal structure, surface morphology, cycling tests, as well as AC impedance were discussed in this study.

\section{EXPERIMENTAL}

\subsection{Samples Preparation}

Graphene nanosheet (SFG44-GNS) derived from SFG44 synthetic graphite powders (TIMCAL $\AA$ ) were synthesized by the modified Hummers' method $^{11}$ described in detail as follows: $8 \mathrm{~g}$ graphite powder and $4 \mathrm{~g} \mathrm{NaNO}_{3}$ were put into $560 \mathrm{ml}$ concentrated $\mathrm{H}_{2} \mathrm{SO}_{4}$ solution with stirring for 2 hours. Then $24 \mathrm{~g} \mathrm{KMnO}_{4}$ was gradually added into the flask with ice bath for 2 hours. The mixture was diluted by $800 \mathrm{ml}$ de-ionized water (DI water). After that, $5 \% \mathrm{H}_{2} \mathrm{O}_{2}$ was added into the solution until the color of the mixture changed to brown, indicating fully oxidized graphite was obtained. The as-obtained graphite oxide slurry was re-dispersed in DI water. Then, the mixture was washed by $0.1 \mathrm{M} \mathrm{HCl}$ solution to remove $\mathrm{SO}_{4}{ }^{2-}$ ions. Finally, the product was washed with DI water to remove the residual acid until the $\mathrm{pH}$ was reached to $\sim 7$. By cleaning with DI water, filtrating and drying in vacuum for $24 \mathrm{~h}$ (the obtaining powders were graphene oxide, namely SFG44-GO). The GO powder was subsequently reduced at $300^{\circ} \mathrm{C}$ for 2 hours under a reducing atmosphere of $15 \% \mathrm{H}_{2} / 85 \% \mathrm{~N}_{2}$, namely SFG44-GNS-300. 


\subsection{Electrodes Preparations}

The composite electrode consists of 89 wt.\% SFG44GNS-300, 1 wt.\% Super-P (40nm, TIMCAL) as conductive additive and $10 \mathrm{wt} . \%$ water-based-binders of SBR and CMC [12]. The mixed-slurry was coated on $\mathrm{Cu}$-foil with a final film thickness of $\sim 50 \mu \mathrm{m}$. CR2032 coin cells were fabricated from the electrode for electrochemical characterizations. The bare SFG44 graphite electrode was prepared in the same way. The counter electrode is lithium foil. The electrolyte is $1 \mathrm{M} \mathrm{LiPF}_{6}$ in ethylene carbonate (EC): ethyl methyl carbonate (EMC) (1:2 vol. \%) from Mitsubishi. All the potentials reported herein are referenced to Li. The current densities refer to masses excluding binder and conductive additives.

\subsection{Characterizations}

Cyclic voltammetry (CV) analysis was performed between $0.05 \mathrm{~V}$ to $3.0 \mathrm{~V}$ at $5 \mathrm{mV} / \mathrm{min}$. The charge/discharge $(\mathrm{C} / \mathrm{D})$ tests were carried out with a constant-current-constant voltage (CC-CV) mode within the voltage range from 0.001 to $3.5 \mathrm{~V}$. The CC process employed a current of $0.1 \mathrm{~mA} / \mathrm{mg}$, while the CP process was fixed to $0.001 \mathrm{~V}$ with a cut-off current of $0.03 \mathrm{~mA} / \mathrm{mg}$. The morphologies of the synthesized graphene material were examined by scanning electron microscopy (SEM; LEO1530). Transmission electron microscopy (TEM) analysiswas conducted with a fieldemission transmission electron microscope (FE-TEM, JEOL JEM-2100F). X-ray diffraction (XRD) was carried out on a Mac-Science/MXP diffractometer with $\mathrm{CuK \alpha}$ radiation. Thermal gravimetrical analysis _TGA_was performed by using an Ulvac TGD-7000 at a scanning rate of $10^{\circ} \mathrm{C} \mathrm{min}^{-1}$.

\section{RESULTS AND DISCUSSION}

\subsection{Thermogravimetric Analysis and Crystal Structure of Graphene-Based Materials}

Fig. (1) shows the TGA and its derivative curves of SFG44-GO with a heating rate of $10{ }^{\circ} \mathrm{C} / \mathrm{min}$ in inert atmosphere. Two apparent weight loss at $33^{\circ} \mathrm{C}$ and $216^{\circ} \mathrm{C}$ were observed in SFG44-GO, which might be attributed to the desorption of adsorbed water and decomposition of functional groups including hydroxyl and carboxylic groups, respectively. The result indicates that the functional groups derived from oxidative exfoliation process could be almost eliminated by post heating process as long as the temperature is above $300^{\circ} \mathrm{C}$.

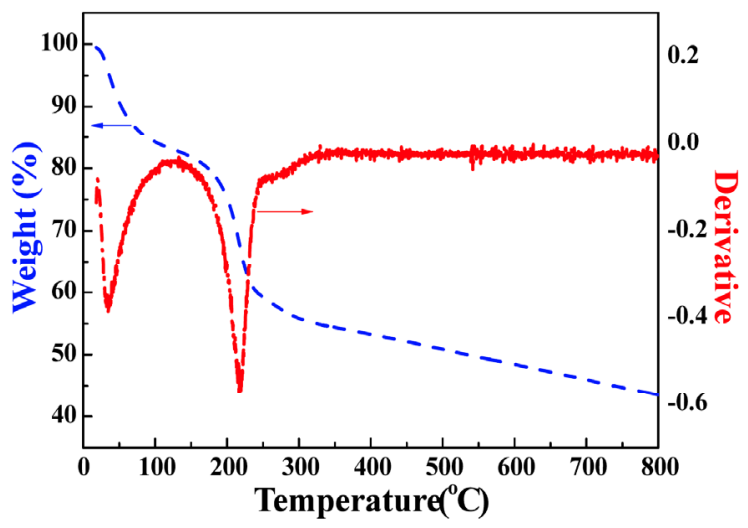

Fig. (1). TGA curves of SFG44-GO with a heating rate of 10 ${ }^{\circ} \mathrm{C} / \mathrm{min}$.
Fig. (2) displays the XRD patterns of bare SFG44, SFG44-GO and SFG44-GNS-300, respectively. Before exfoliation treatment, highly crystalline SFG44 give a sharp diffraction peaks, of which crystallite size exceeding $30 \mathrm{~nm}$ determined by Scherrer equation. The d-spacing of SFG44 could be calculated to be $0.335 \mathrm{~nm}$ according to (002) reflection. After exfoliation and oxidation by modified Hummer's method, the obtained SFG44-GO showed a typical diffraction peak at $12^{\circ}\left(\mathrm{d}_{002} \sim 7.4 \AA\right)$. SFG44G, being reduced with hydrazine, almost showed amorphous nature, of which average d-spacing could be roughly determined as $0.375 \mathrm{~nm}$.; in the meanwhile, $300^{\circ} \mathrm{C}$ calcined sample (SFG44-GNS-300) showed a larger d-spacing to $0.3407 \mathrm{~nm}$ and amorphous nature. These properties are similar to that of hard carbon, which may good for reversible capacity and rate capability.

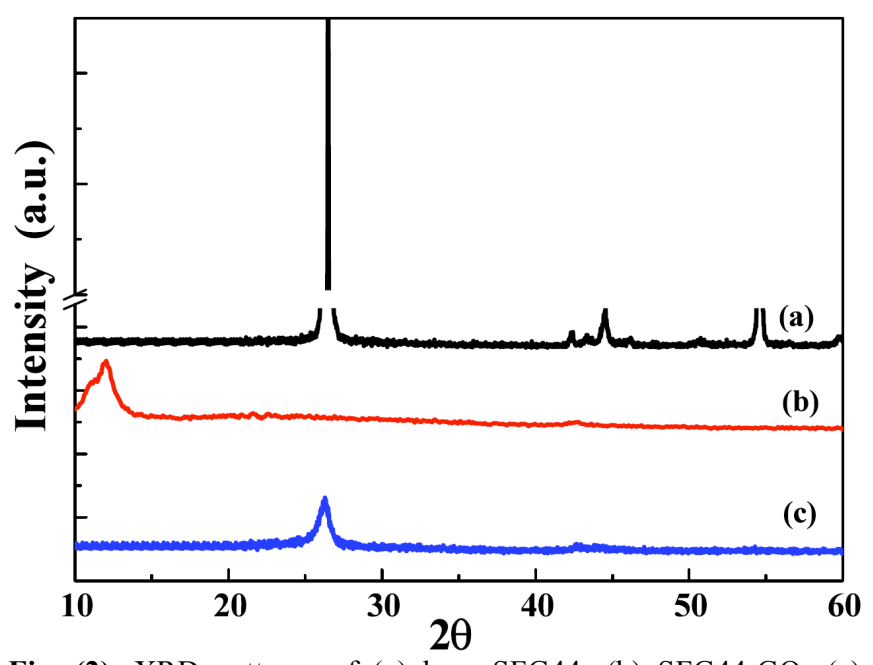

Fig. (2). XRD patterns of (a) bare SFG44; (b) SFG44-GO; (c) SFG44-GNS-300.

\subsection{Surface Morphologies and Cross-Section Images of Graphene-Based Materials}

The SEM micrographs of SFG44 and SFG44-GNS-300 are shown in Fig. (3A, B), respectively. SFG44 graphite is a flake-like structure with very dense nature on the surface. SFG44-GNS-300, on the other hand, displayed a flower-like morphology with porous structure, in which the penetration of both electrolyte and $\mathrm{Li}$-ion would be much easier. The porous structure SFG44-GNS-300 with fewer layers could provide not only additional cites for lithium ions, but also to occupy and facilitate the kinetics of lithium for insertion/extraction. Fig. (4A, B) illustrates the TEM micrographs of SFG44 and SFG44-GNS-300. The $\mathrm{d}_{002}$ and graphene layers of SFG44 were $\sim 0.332 \mathrm{~nm}$ and $\sim 100$ layers, respectively. After exfoliation process, d-spacing and thickness of SFG44-GNS-300 were observed to be $0.352 \mathrm{~nm}$ $\sim 0.511 \mathrm{~nm}$ and 10 40 layers, respectively. The inset in Fig. (4B) displays the SEM micrograph giving a soft and flexible nature due to the thickness of graphite could be efficiently reduced by exfoliation process.

\subsection{Raman and BET Analyses of Graphene-Based Materials}

Fig. (5) shows Raman spectra of bare SFG44, SFG44GO and SFG44-GNS-300. Raman spectroscopy is a direct and non-destructive measurement for characterization of 

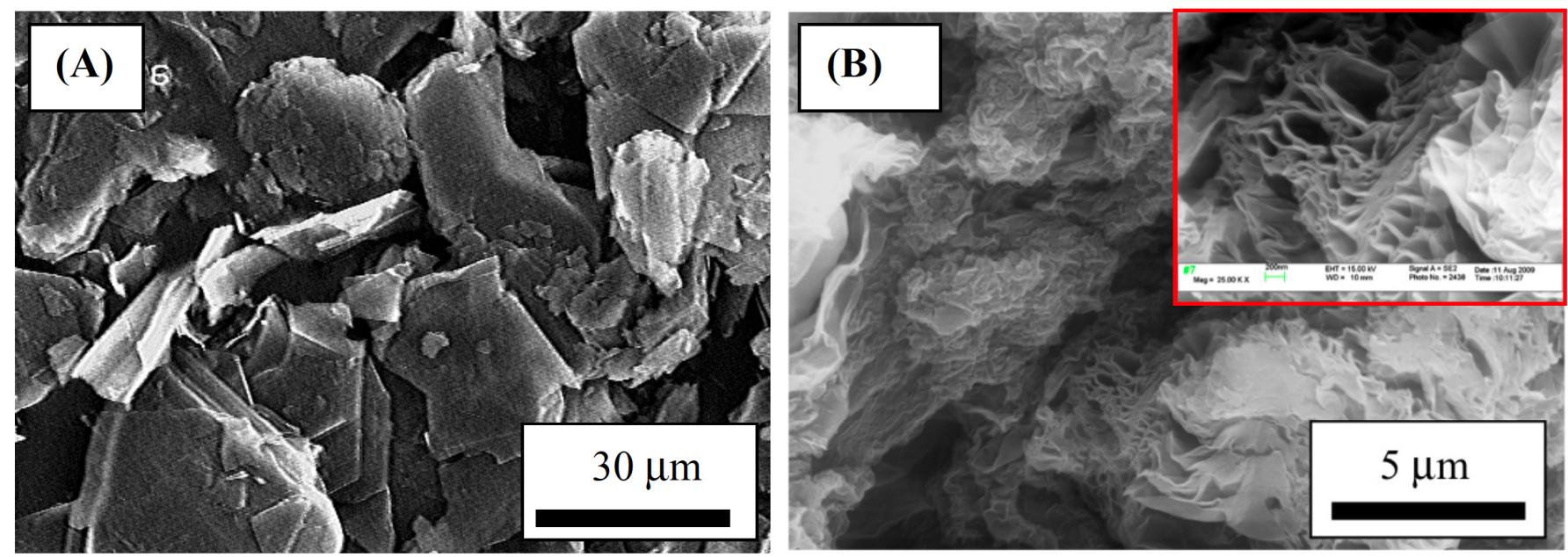

Fig. (3). SEM micrographs of graphite w/wo exfoliation process: (A) bare SFG44; (B) SFG44-GNS-300. The inset: larger magnitude image of SFG44-GNS-300.
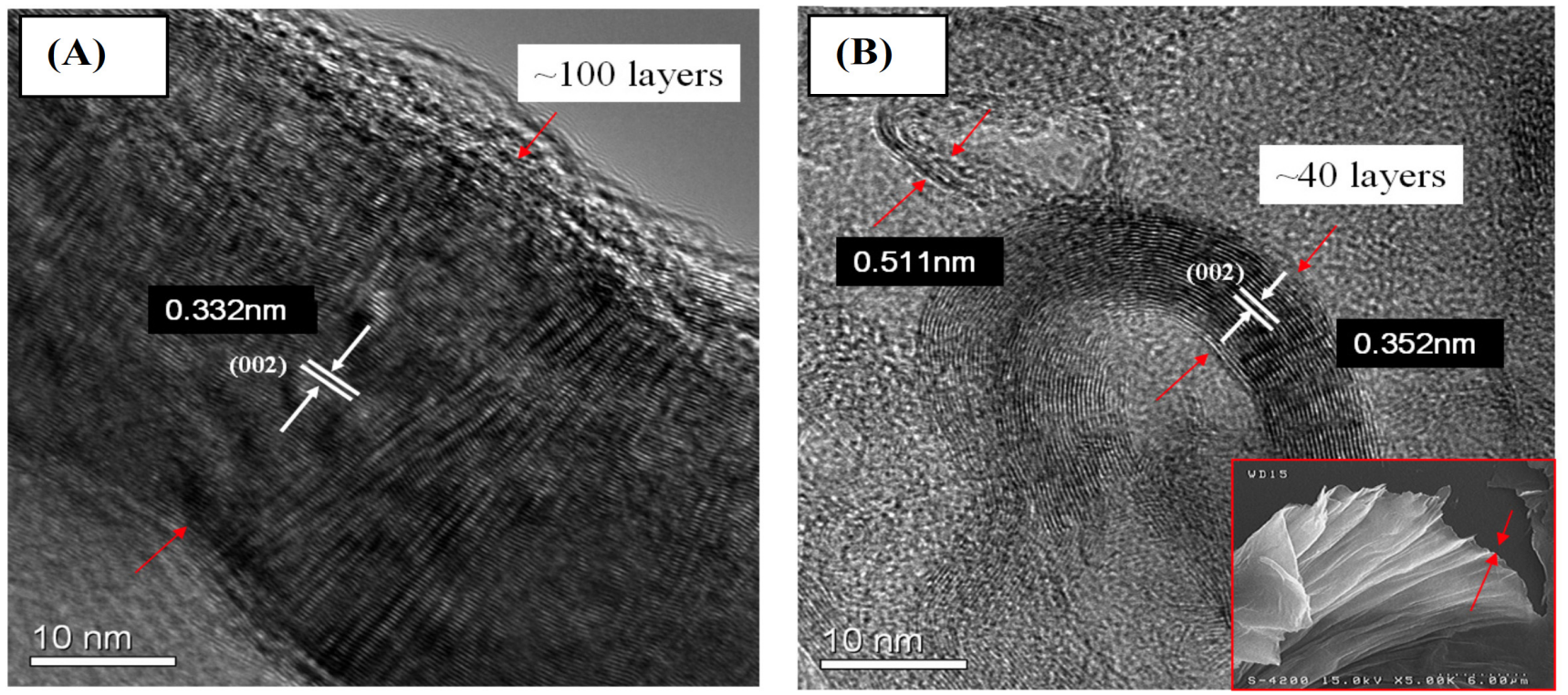

Fig. (4). (A) TEM micrographs of the SFG44 and (B) SFG44-GO. The inset shows the graphene with soft nature.

disorder structure of graphitic materials. Two characteristic peaks generally named by $\mathrm{D}\left(\sim 1355 \mathrm{~cm}^{-1}\right)$ and $\mathrm{G}\left(\sim 1580 \mathrm{~cm}^{-1}\right)$ bands were observed in graphite-based materials. The $\mathrm{G}$ band represents the first order scattering of the $E_{2 g}$ photons observed for $\mathrm{sp}^{2}$ carbon domain, while the $\mathrm{D}$ band corresponds to breathing mode or j-point photons of $\mathrm{A}_{1 \mathrm{~g}}$ symmetry associated with disorder band of structural defect, amorphous carbon or edge. The intensity ratio of $\mathrm{D}$ band to $\mathrm{G}$ band $\left(\mathrm{I}_{\mathrm{D}} / \mathrm{I}_{\mathrm{G}}\right)$ is usually used as a measure of disorder. In comparison to bare graphite, both SFG44-GO and SFG44GNS-300 showed broader $\mathrm{G}$ band accompanying with board $\mathrm{D}$ band, indicative of a highly disorder in graphitic structure. It shows that even most functional groups were removed by the reduction process, the $\mathrm{sp}^{3}$ could not be restored to original $\mathrm{sp}^{2}$ graphitic structure. In addition, there is no significant decrease in $\mathrm{I}_{\mathrm{D}} / \mathrm{I}_{\mathrm{G}}$ ratio for graphene nanosheets after high temperature reduction, even re-crystallization process was observed in XRD patterns. It is indicative of the functional groups derived from oxidation process could be removed but $\mathrm{sp}^{3}$ dangling bond could not be restored to original $\mathrm{sp}^{2}$ graphene structure.

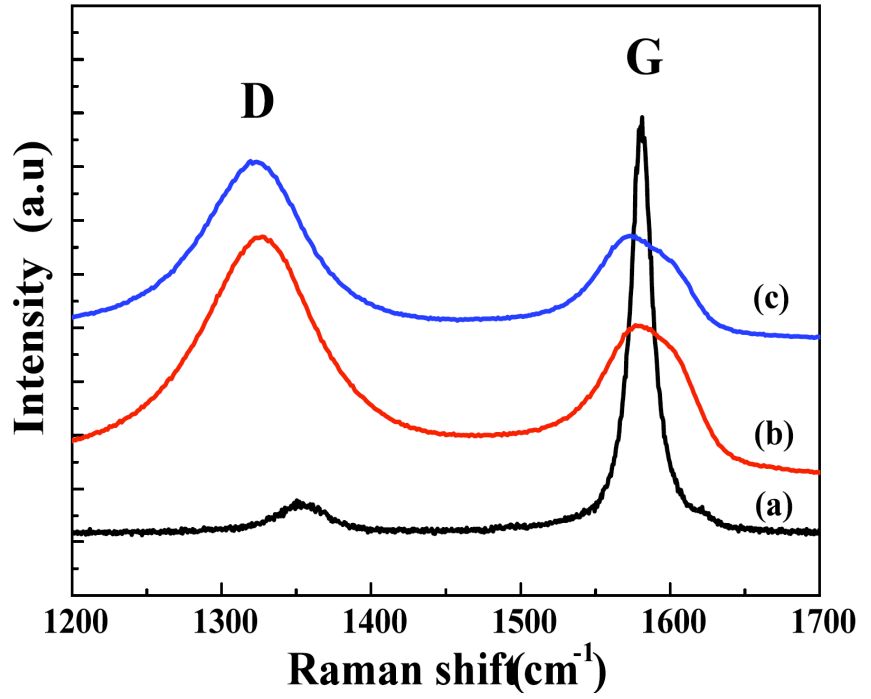

Fig. (5). Raman spectra of (a) bare SFG44, (b) SFG44-GO and (c) SFG44-GNS-300. 

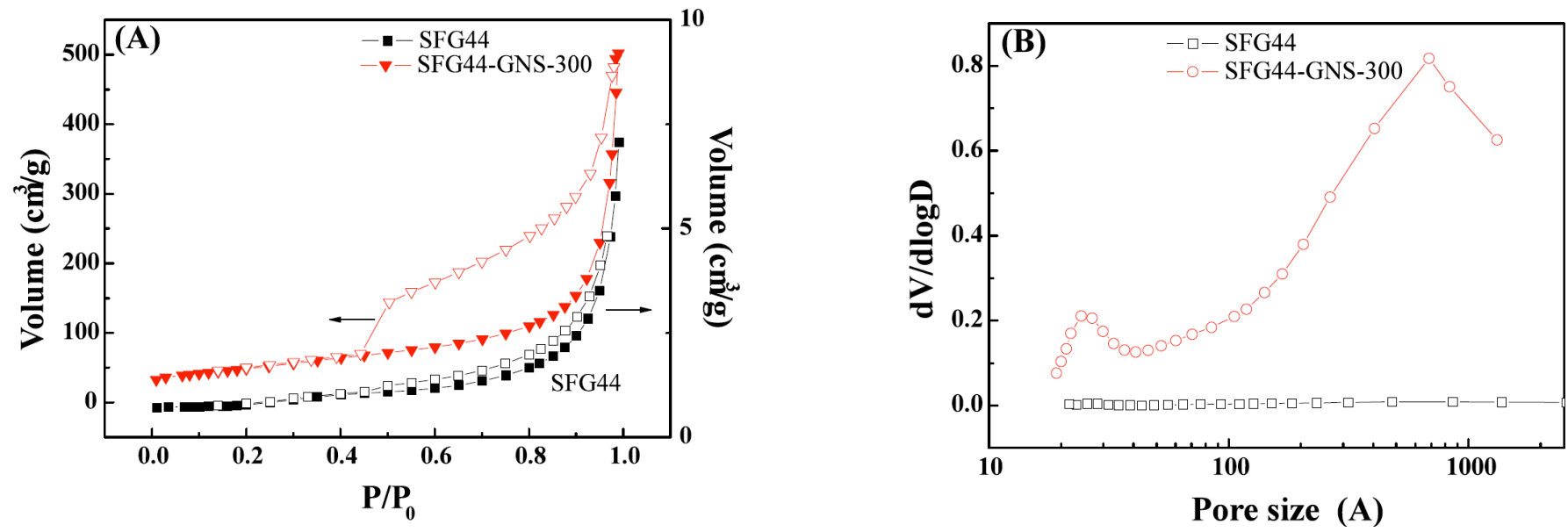

Fig. (6). (A) Isotherm adsorption/desorption curves of bare SFG44 and SFG44-GNS-300; (B) Pore size distribution of as-bare SFG44 and SFG44-GNS-300.

Fig. (6A) shows isotherms and pore size distributions of SFG44 and SFG44-GNS-300. The BET surface area of SFG44 graphite was $2.61 \mathrm{~m}^{2} \mathrm{~g}^{-1}$. By exfoliation process, the BET of SFG44-GNS-300 could be dramatically enhanced by $171 \mathrm{~m}^{2} \mathrm{~g}^{-1}$. The value of BET for SFG44-GNS-300 is much smaller than theoretical value of graphene of $2620 \mathrm{~m}^{2} \mathrm{~g}^{-1}$, indicative of SFG44-GNS-300 sample was not fully exfoliated to single layer graphene instead of few-layers graphene. The $\mathrm{BJH}$ pore size distributions were shown in Fig. (6B). The main pore size belongs to meso-pore, where the micro pore portion was not dominant. The larger BET and pore volume could not only provide additional cites for Li-ion to occupy, but also facilitate the kinetics of $\mathrm{Li}$ intercalation/extraction processes.

\subsection{Electrochemical Tests of Graphene-Based Materials}

Fig. (7A, B) show the CV curves of SFG44 and SFG44GNS-300 at the first second cycles. The CV curves of SFG44 exhibited a typical sharp reduction/oxidation peaks at $\sim 0.15 \mathrm{~V}$ and $0.23 \mathrm{~V}$, respectively. After exfoliation, the electrochemical behavior definitely differed from that of graphite. The reduction/oxidation peaks become much broaden in the first two cycles in Fig. (6B). The lithiumintercalation reactive potential increased from $\sim 0.15 \mathrm{~V}$ to $\sim 0.6 \mathrm{~V}$, which indicates the kinetics of lithium and graphene

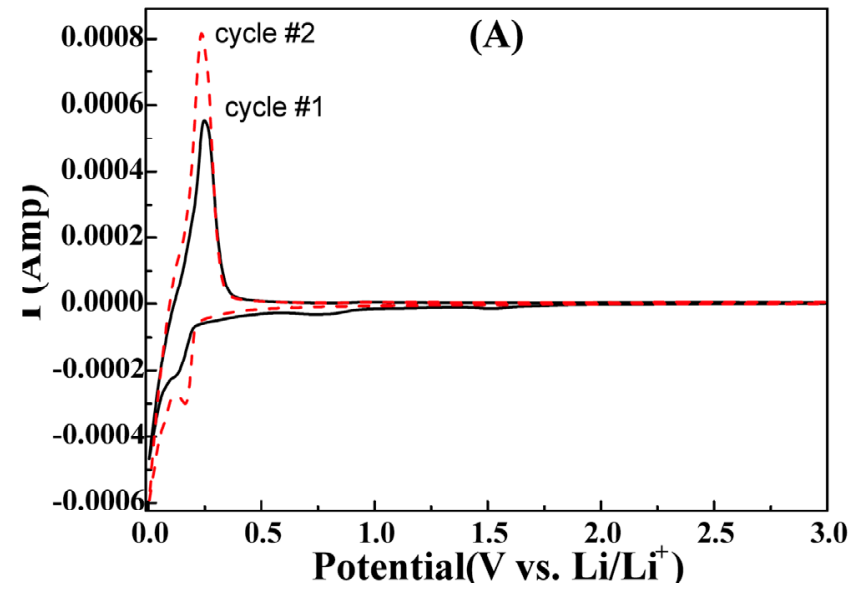

was higher than that of graphite. In order words, the energy barriers of diffusion and reaction of $\mathrm{Li} / \mathrm{C}$ were lower for graphene anodes compared to graphite. For de-intercalation process, two broad hums peaking between $0.01 \mathrm{~V}$ to $3.0 \mathrm{~V}$ were observed in Fig. (7B). The higher potential of deintercalation could be responsible for some lithium ions were tightly trapped in the structure defects due to the amorphous nature of graphene.

Fig. $(\mathbf{8 A}, \mathbf{B})$ shows the $\mathrm{C} / \mathrm{D}$ curves of SFG44 and SFG44-GNS-300 in the first two cycles. The $1^{\text {st }}$ and $2^{\text {nd }}$ reversible capacity of SFG44 were $334 \mathrm{mAh} \mathrm{g}^{-1}$ and 327 $\mathrm{mAh}{ }^{-1}$, respectively: in the meanwhile, the irreversibility of the $1^{\text {st }}$ cycle was $21.7 \%$. The discharging plateau (lithiuminsertion) of SFG44 was observed to be $\sim 0.05 \mathrm{~V}$, which is graphite-like behavior. On the other hand, SFG44-GNS-300 showed the extremely high reversible capacities, $626 \mathrm{mAh} \mathrm{g}^{-}$ ${ }^{1}$ and $561 \mathrm{mAh} \mathrm{g}^{-1}$ for the $1^{\text {st }}$ and $2^{\text {nd }}$ cycle, and irreversibility of the $1^{\text {st }}$ cycle is about $51.9 \%$. Yoo et al., demonstrate that the layer of graphene is a function of d-spacing as well as charge capacity [8]. In our case, the average d-spacing of assynthesized graphene is $\sim 0.375 \mathrm{~nm}$ estimated by XRD. According to fitting data of Yoo's group, the reversible charge capacity of as-synthesized graphene is around 600 $\mathrm{mAh} \mathrm{g}^{-1}$, which is in consistent with our results.

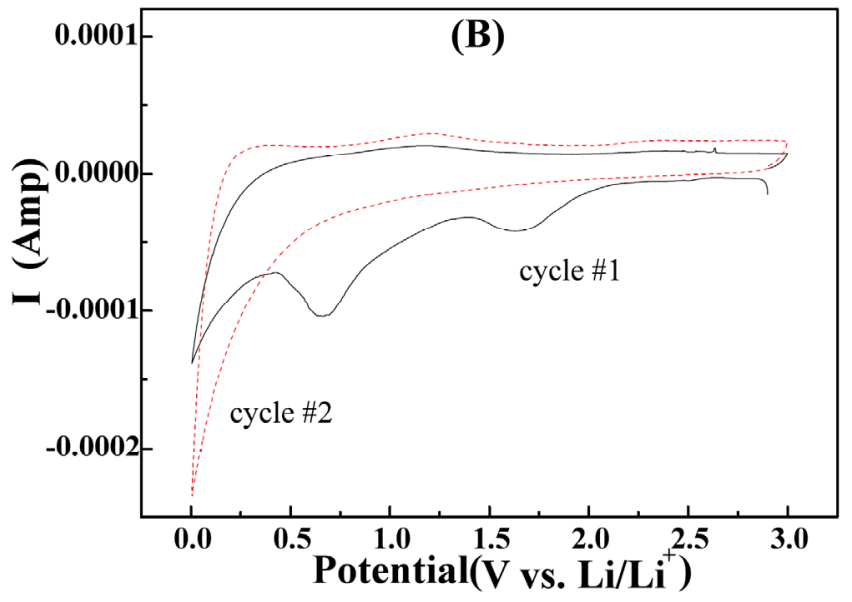

Fig. (7). CV curves of graphite w/wo exfoliation process for the first two cycles: (A) SFG44; (B) SFG44-GNS-300. 

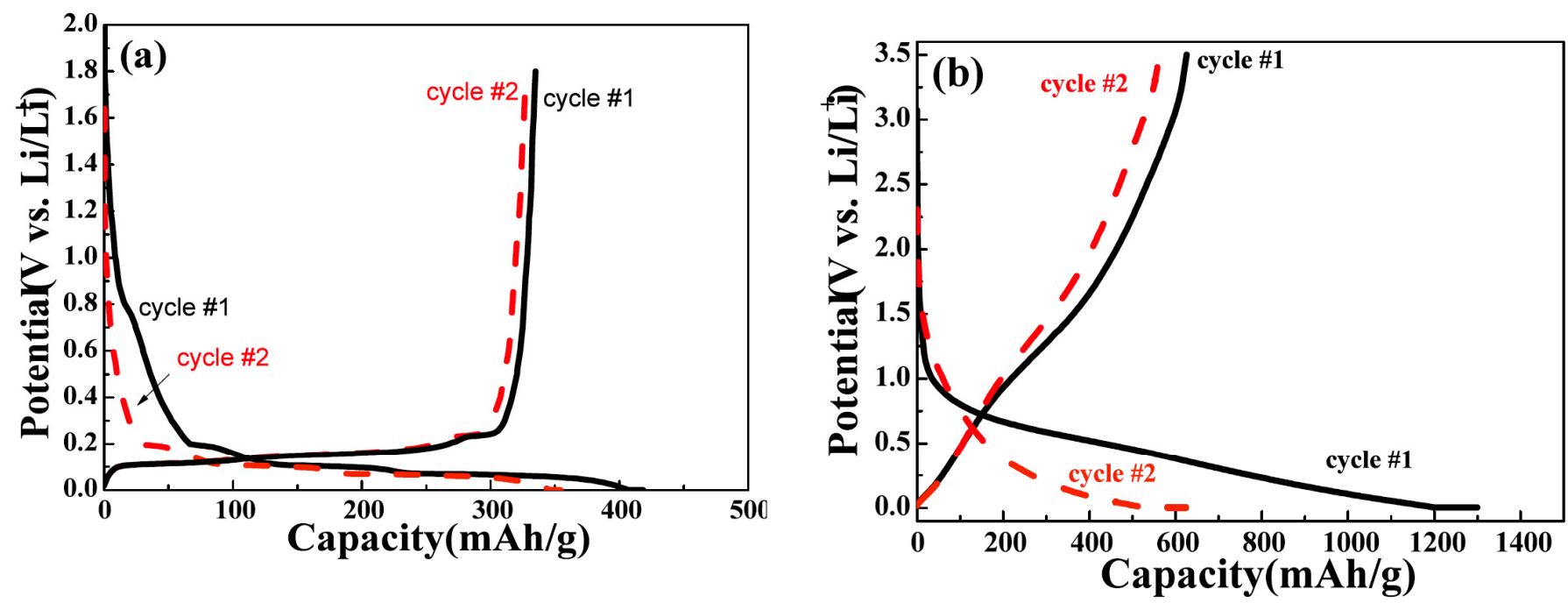

Fig. (8). Charge/discharge curves in the first two cycles at 0.1C: (a) SFG44 and (b) SFG44-GNS-300.

Nevertheless, the large irreversible capacity loss of graphene-based anode in the first cycle was also reported by many groups in the range of $50 \sim 80 \%$. The possible reasons could be ascribed to (i) larger specific surface area; (ii) structure defects; (iii) function groups and (iv) SEI (solid electrolyte interface). The reducing of irreversible capacity loss for graphene-based anode materials would be the most important issue for their application on LIBs. In the present results, the irreversible capacity loss of graphene was mainly attributed to higher surface area, structure defects and SEI. Which is the main factor is worthy to discuss in the future work.

Fig. (9) shows the cycling tests of SFG44 and SFG44GNS-300 for 30 cycles with charging/discharge currents of $0.2 \mathrm{C}$. SFG44 graphite gived a reversible capacity of $\sim 334$ $\mathrm{mAh}{ }^{-1}$ with fair cyclability. The SFG44-GNS-300 sample, on the other hand, exhibited $\sim 600 \mathrm{mAh} \mathrm{g}^{-1}$ in the first cycyle and retained $280 \mathrm{mAh} \mathrm{g}^{-1}$ after 30 cycles. The inset of Fig. (9) displays the charge capacity of SFG-44 and SFG44GNS-300 with different $\mathrm{C}$ rates. With $2 \mathrm{C}$ discharge, the capacity of SFG44-GNS-300 is as high as $300 \mathrm{mAh} \mathrm{g}^{-1}$ $(\sim 50 \%$ of $0.2 \mathrm{C})$. The capacity of SFG44 graphite is only 75

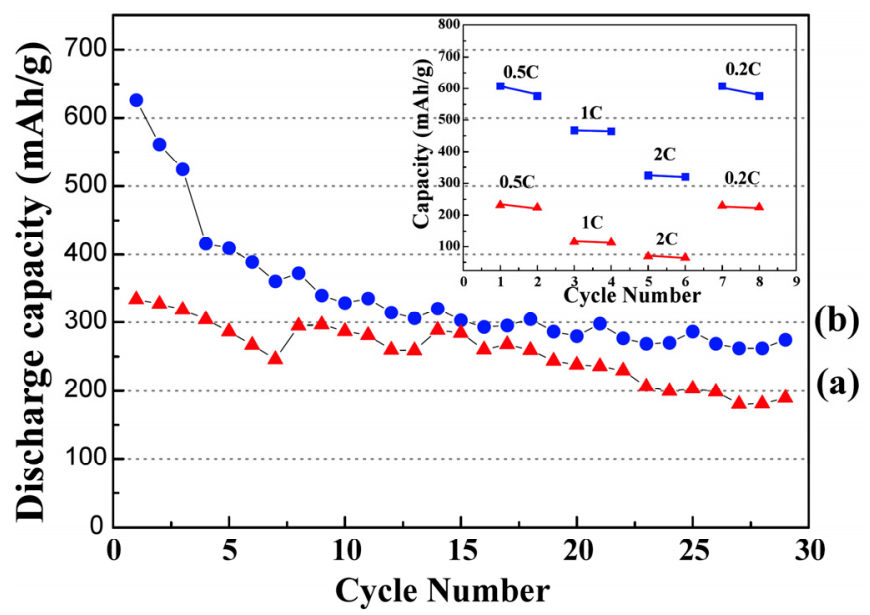

Fig. (9). Cycling tests of SFG44 (a) and SFG44-GNS (b) at $0.2 \mathrm{C}$. The inset shows their rate capability.
mAh $\mathrm{g}^{-1}$ at $2 \mathrm{C}(\sim 22 \%$ of $0.2 \mathrm{C})$. The results surprisingly showed that the SFG44-GNS-300 exhibited better rate capability than that of graphite sample. The impedance data of these two samples in discharging state of $0.01 \mathrm{~V}$ at the $4^{\text {th }}$ cycle are shown in Fig. (10). The result future demonstrated that the charge transfer resistance of SFG44-GNS-300 was lower than that of SFG44 graphite, which indicates that the good rate capability could be explained by the lower impedance for SFG44-GNS-300. Thus, the graphene-based anode materials might be good anode materials for EV or HEV applications due to their good performance with high rate charge/discharge tests.

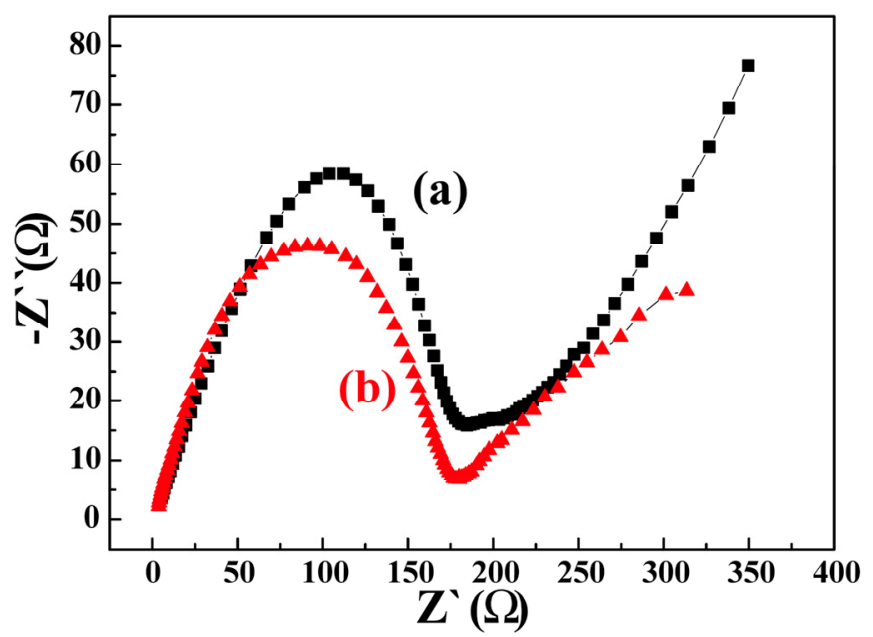

Fig. (10). AC impedance spectra for SFG44 (a) and SFG44-GNS300 (b) with discharging state of $0.01 \mathrm{~V}$ at the $4^{\text {th }}$ cycle.

\section{CONCLUSIONS}

In summary, SFG44-GNS-300 is synthesized by modified Hummers' method. The relationship between electrochemical performance, such as reversible capacity, rate capability and irreversible capacity, and structure characterization of BET, pore distribution and surface morphology, are discussed by means of charge/discharge tests, rate capability tests, BET, as well as Raman spectroscopy and XRD measurements. These corresponding results could be the reference for structure design of 
graphene-based anode for the application of Li-ion batteries in the future.

\section{ACKNOWLEDGEMENTS}

The work is financially supported from ITRI under contract no. A301AR4830 and the NSC (contract no. NSC96-2221-E-155-055-MY2-2).

\section{REFERENCES}

[1] Idota Y, Kubota T, Matsufuji A, Maekawa Y, Miyasaka T. Tinbased amorphous oxide: a high-capacity lithium-ion-storage material. Science 1997; 276: 1395-7.

[2] Maier J. Nanoionics: ion transport and electrochemical storage in confined systems. Nat Mater 2005; 4: 805-15.

[3] Loi XW, Wang Y, Yuan C., Lee JY, Archer LA. Template-free synthesis of $\mathrm{SnO}_{2}$ hollow nanostructures with high lithium storage capacity. Adv Mater 2006; 18: 2325.

[4] Chan CK, Zhang XF, Cui Y. High capacity Li-ion battery anodes using Ge nanowires. Nano Lett 2008; 8: 307-9.
[5] Kim DW, Hwang IS, Kwon SJ, et al. Highly conductive coaxial $\mathrm{SnO}_{2}-\mathrm{In}_{2} \mathrm{O}_{3}$ heterostructured nanowires for li-ion battery electrodes. Nano Lett 2007; 7: 3041-5.

[6] Paek SM, Yoo E, Honma I. Enhanced cyclic performance and lithium storage capacity of $\mathrm{SnO}_{2} /$ graphene nanoporous electrodes with three-dimensionally delaminated flexible structure. Nano Lett 2009; 9: 72-5.

[7] Yao J, Shen X, Wang B, Liu H, Wang G. In situ chemical synthesis of $\mathrm{SnO}_{2}$-graphene nanocomposite as anode materials for lithiumion batteries. Electrochem Commun 2009; 11: 1849-52.

[8] Yoo E, Kim J, Hosono E, Zhou HS, Kudo T, Honma I. Large reversible Li storage of graphene nanosheet families for use in rechargeable lithium ion batteries. Nano Lett 2008; 8: 2277-82.

[9] Wang G, Shen X, Yao J, Park J, Graphene nanosheets for enhanced lithium storage in lithium ion batteries. Carbon 2009; 47: 2049-53.

[10] Chou SL, Wang JZ, Choucair M, Liu HK, Stride JA. Enhanced reversible lithium storage in a nanosize silicon/graphene composite. Electrochem Commun 2010; 12: 303-6.

[11] Hummers WS, Offeman RE, Preparation of graphitic oxide. J Am Chem Soc.1958; 80: 1339.

[12] Liu WR, Yang MH, Wu HC, Chiao SM, Wu NL. Enhanced cycle life of Si anode for li-ion batteries by using modified elastomeric binder. Electrochem Solid State Lett 2005; 8: A100-3. 